\title{
Evaluation of Bulk Modulus of Oil System with Hydraulic Line
}

\author{
L. Hružík ${ }^{1}$, M. Vašina ${ }^{2}$, and A. Bureček ${ }^{1}$ \\ ${ }^{1}$ VŠB - Technical University of Ostrava, Faculty of Mechanical Engineering, Department of Hydromechanics and \\ Hydraulic Equipment, 70833 Ostrava, Czech Republic \\ ${ }^{2}$ Tomas Bata University in Zlín, Faculty of Technology, Department of Physics and Materials Engineering, 76001 \\ Zlín, Czech Republic
}

\begin{abstract}
The aim of the paper is to experimentally measure and evaluate bulk modulus of oil/steel pipe system and oil/hose system. The measurement was performed using experimental device on the basis of a measured pressure difference depending on time. Bulk modulus is evaluated from pressure change with known flow and volume of line. Pressure rise is caused by valve closure at the line end. Furthermore, a mathematical model of the experimental device is created using Matlab SimHydraulics software. Time dependencies of pressure for the oil/steel pipe system and the oil/hose system are simulated on this mathematical model. The simulations are verified by experiment.
\end{abstract}

\section{Introduction}

Oil bulk modulus of elasticity as the reciprocal of volume compressibility belongs to important properties of hydraulic oils. In practise, a stiff system is most often required. For this reason it is necessary to achieve the highest oil bulk modulus of elasticity. Bulk modulus of elasticity depends on many factors, e.g. on pressure, temperature and undissolved air volume. An amount of undissolved air has the greatest influence on hydraulic oil bulk modulus of elasticity due to high air volume compressibility compared to oil volume compressibility. This fact has an influence on speed of response and also on whole dynamics of a given hydraulic system [2, 3, 4, 7].

\section{Types of oil bulk modulus of elasticity}

There are four types $[1,3,5,6]$ of bulk modulus of elasticity:

1. Isothermal secant bulk modulus,

2. Isothermal tangent bulk modulus,

3. Adiabatic secant bulk modulus,

4. Adiabatic tangent bulk modulus.

The difference between isothermal and adiabatic oil bulk modulus of elasticity is given by compression speed. The isothermal process occurs at slow pressure changes. In the case of high speed changes in pressure, the process is adiabatic. Bulk modulus of elasticity is also divided into secant and tangent (see figure 1). The secant modulus is more suitable for big pressure changes. The tangent modulus is more applicable for small dynamic pressure changes.

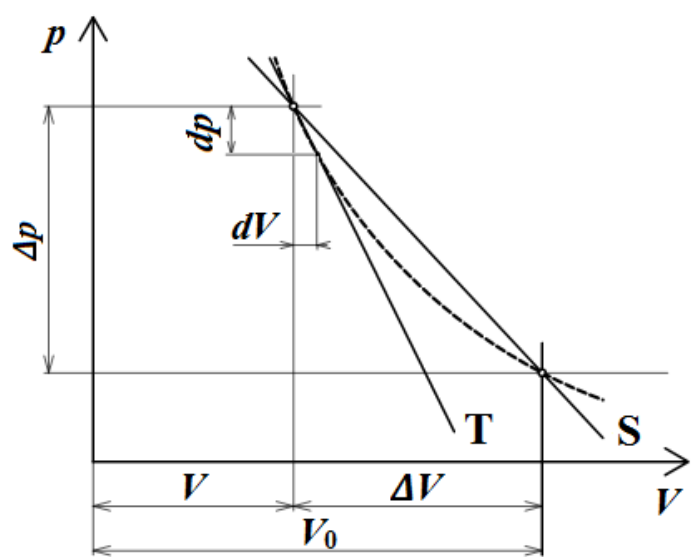

Fig. 1. Determination of the secant $(\mathrm{S})$ and the tangent $(\mathrm{T})$ liquid bulk modulus of elasticity.

The secant modulus of elasticity $K_{\mathrm{S}}$ is defined by the equation [3]:

$$
K_{\mathrm{s}}=\Delta p \cdot \frac{V_{0}}{V_{0}-V}=\Delta p \cdot \frac{V_{0}}{\Delta V}
$$

The tangent modulus of elasticity $K_{\mathrm{T}}$ is defined by the formula [3]:

$$
K_{\mathrm{T}}=V \cdot \frac{d p}{d V},
$$

where $V_{0}$ initial oil volume, $\mathrm{m}^{3} ; V$ oil volume after compression, $\mathrm{m}^{3} ; \Delta V$ oil volume change, $\mathrm{m}^{3} ; \Delta p$ pressure change, $\mathrm{Pa}$. 


\section{Descriptions of experiment experimental equipment}

Hydraulic oil flows from the hydraulic pump HP through the check valve $\mathrm{CV}$, the directional valve $\mathrm{V}$, the hose $\mathrm{H} 1$, the flow sensor FS, the pipes P1, P and P2 and the hose $\mathrm{H} 2$ into the tank $\mathrm{T}$. The experimental equipment also consists of the relief valve RV, the stop valves SV1-SV6, the measuring tube MT, the hose $\mathrm{H}$, the measuring points MP1 and MP2, the pressure sensors PS1 and PS2, the manometer $\mathrm{M}$ and the measuring equipment M5050 (see figure 3). The dimensions of pipes and hoses for further calculations are the following:

1. Pipe $\mathrm{P}-$ length $l_{\mathrm{P}}=1.642 \mathrm{~m}$, outside diameter $D_{\mathrm{P}}=0.03 \mathrm{~m}$, inside diameter $d_{\mathrm{P}}=0.022 \mathrm{~m}$, wall thickness $s_{\mathrm{P}}=0.004 \mathrm{~m}$, Young's modulus of elasticity $E_{\mathrm{P}}=2.1 \times 10^{11} \mathrm{~Pa}$.

2. Hose $\mathrm{H}-$ length $l_{\mathrm{H}}=1.39 \mathrm{~m}$, outside diameter $D_{\mathrm{H}}=0.018 \mathrm{~m}$, inside diameter $d_{\mathrm{H}}=0.01 \mathrm{~m}$.

3. Pipe $\mathrm{P} 1-$ length $l_{\mathrm{P} 1}=4.5 \mathrm{~m}$, outside diameter $D_{\mathrm{P} 1}=0.016 \mathrm{~m}$, inside diameter $d_{\mathrm{P} 1}=0.012 \mathrm{~m}$.

4. Hose $\mathrm{H} 1$ - length $l_{\mathrm{H} 1}=0.65 \mathrm{~m}$, outside diameter $D_{\mathrm{H} 1}=0.024 \mathrm{~m}$, inside diameter $d_{\mathrm{H} 1}=0.016 \mathrm{~m}$.

5. Measuring tube MT - inside diameter $d_{0}=0.0098 \mathrm{~m}$.

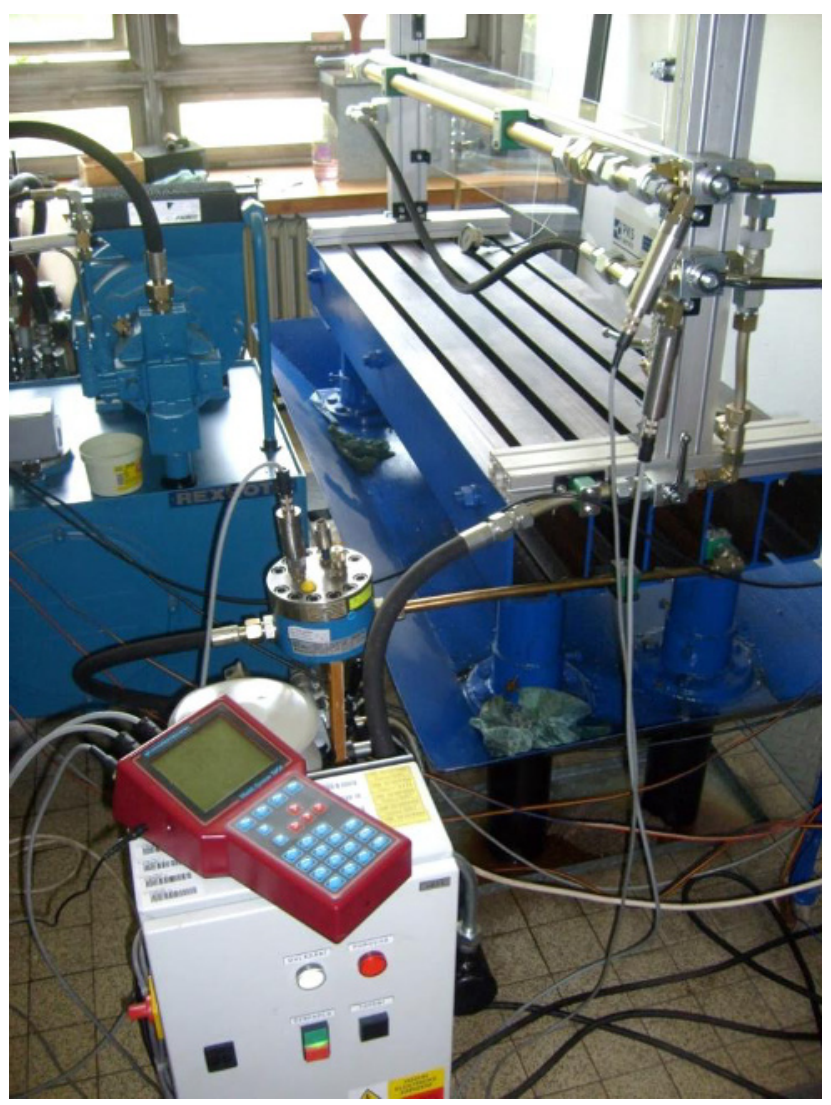

Fig. 2. Picture of experimental circuit.

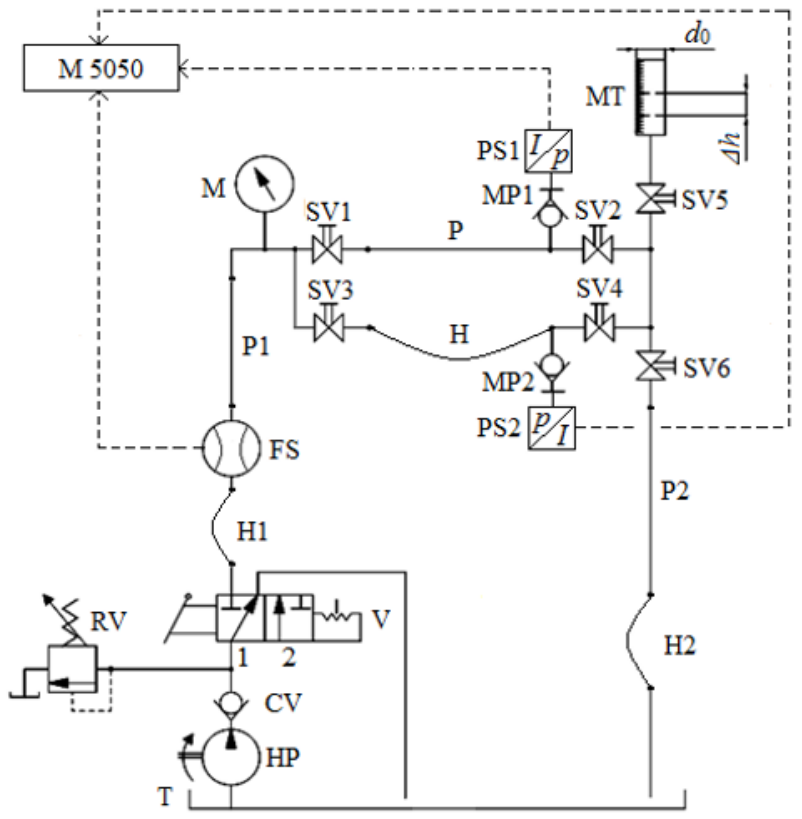

Fig. 3. Scheme of experimental circuit.

\subsection{Determination of bulk modulus based on volume change}

Figure 3 shows the experimental equipment for the determination of oil bulk modulus of elasticity in oil/steel pipe system and oil/hose system. The principle of its determination in the oil/pipe system consists in measurement of the oil level change $\Delta h$ (see figure 3) before and after the discharge of compressed oil in the pipe $P$. The required pressure is initially adjusted on the relief valve $\mathrm{RV}$. The directional valve $\mathrm{V}$ is in the position 2. The stop valve SV2 is subsequently closed. After reaching the set pressure on the relief valve $R V$, the stop valve SV6 is closed. Furthermore, the stop valve SV5 is open. Subsequently, the stop valve SV1 is closed and the stop valve SV2 is open. The working pressure is now reduced to atmospheric pressure by the value $\Delta p$. Compressed oil flows into the measuring tube MT, in which the oil level is changed (i.e. the oil level increasing $\Delta h)$. The same principle is valid for the oil/hose system. Only the stop valves SV3 and SV4 are used instead the stop valves SV1 and SV2.

The computation of bulk modulus of elasticity of the oil/pipe system and hydraulic oil is described by the undermentioned relations [7].

The oil volume $V_{\mathrm{O}, \mathrm{P}}$ in the pipe $\mathrm{P}$ is given by the formula:

$$
V_{\mathrm{O}, \mathrm{P}}=\frac{\pi \cdot d_{\mathrm{P}}^{2} \cdot l_{\mathrm{P}}}{4}
$$

The oil volume change $\Delta V_{\mathrm{O}, \mathrm{P}}$ in the measuring tube MT is expressed by the equation:

$$
\Delta V_{\mathrm{O}, \mathrm{P}}=\frac{\pi \cdot d_{0}^{2} \cdot \Delta h}{4} .
$$


The bulk modulus of elasticity $K_{\mathrm{O}, \mathrm{P}}$ of the oil/pipe $\mathrm{P}$ system is defined by:

$$
K_{\mathrm{O}, \mathrm{P}}=\frac{V_{\mathrm{O}, \mathrm{P}} \cdot \Delta p}{\Delta V_{\mathrm{O}, \mathrm{P}}}
$$

The oil bulk modulus of elasticity $K_{\mathrm{O}}$ of the oil/pipe $\mathrm{P}$ system is given by the equation:

$$
K_{\mathrm{O}}=\frac{1}{\frac{\Delta V_{\mathrm{O}, \mathrm{P}}}{V_{\mathrm{O}, \mathrm{P}} \cdot \Delta p}-\frac{d_{\mathrm{P}}}{E_{\mathrm{P}} \cdot s_{\mathrm{P}}}} .
$$

The bulk modulus of elasticity $K_{\mathrm{O}, \mathrm{H}}$ of the oil/hose $\mathrm{H}$ system is determined in a similar manner based on the determination of the oil volume $V_{\mathrm{O}, \mathrm{H}}$ in the hose $\mathrm{H}$ and the oil volume increment $\Delta V_{\mathrm{O}, \mathrm{H}}$ in the measuring tube MT.

The measured values of the bulk modulus of elasticity are adduced in table 1 .

Table 1. The experimentally measured values of the bulk modulus of elasticity (oil temperature $t_{\mathrm{t}}=20^{\circ} \mathrm{C}$ ).

\begin{tabular}{|c|c|c|}
\hline & $\begin{array}{c}\text { Air-containing } \\
\text { system }\end{array}$ & $\begin{array}{c}\text { Partly deaerated } \\
\text { system }\end{array}$ \\
\hline$K_{\mathrm{O}, \mathrm{P}} / 10^{9} \mathrm{~Pa}$ & 1.496 & 1.655 \\
\hline$K_{\mathrm{O}, \mathrm{H}} / 10^{9} \mathrm{~Pa}$ & 0.869 & 0.891 \\
\hline$K_{\mathrm{O}} / 10^{9} \mathrm{~Pa}$ & 1.557 & 1.730 \\
\hline
\end{tabular}

\subsection{Determination of bulk modulus based on pressure increase in time}

Pressure increases depending on time were measured by means of the pressure sensor PS1 and the measuring equipment M 5050. The pressure increase was obtained by closing of the valve SV2 (at the pipe P) or the valve SV4 (at the hose H). The pressure increase was measured in air-containing or partly deaerated systems. These results will be applied to verification of mathematical models. Furthermore, the flow characteristic of the hydraulic pump HP was measured at the temperature $t_{\mathrm{t}}=20^{\circ} \mathrm{C}$ (see figure 4 ).

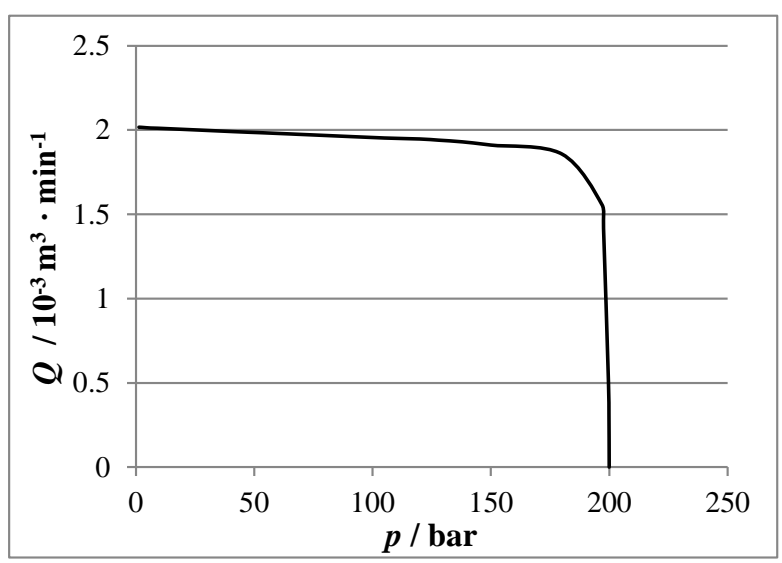

Fig. 4. Flow characteristic of the hydraulic pump HP (oil temperature $t_{\mathrm{t}}=20^{\circ} \mathrm{C}$ ).
It is evident, that the flow $Q$ can be considered as constant up to the pressure $p \cong 150$ bar. The hydraulic pump flow $Q=1.96 \mathrm{dm}^{3} \min ^{-1}$ for the pressure $p=150$ bar was determined from the characteristic (see figure 4).

Figure 5 shows the pressure increase depending on time in the measuring point MP1 (see figure 3) during closing of the stop valve SV2.

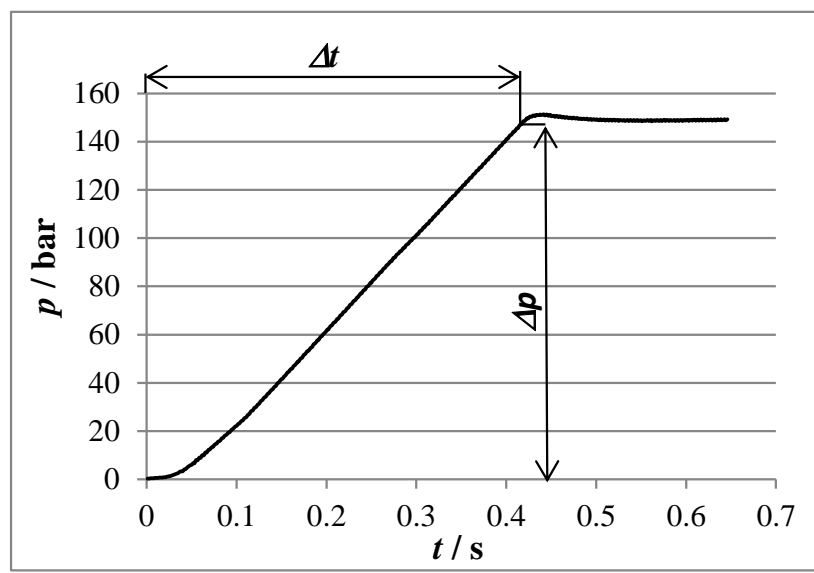

Fig. 5. Pressure increase of the system consisting of H1, P1, P and oil.

The bulk modulus of elasticity $K_{\mathrm{SYS}, \mathrm{P}}$ of the system consisting of the pipes $\mathrm{P} 1$ and $\mathrm{P}$, the hose $\mathrm{H} 1$ and oil is determined by the equation:

$$
K_{\mathrm{SYS}, \mathrm{P}}=\frac{V_{\mathrm{SYS}, 0} \cdot \Delta p}{\Delta V} .
$$

where $V_{\mathrm{SYS}, 0}$ initial oil volume in the system, $\mathrm{m}^{3} ; \Delta p$ pressure change, $\mathrm{Pa}$.

The volume change $\Delta V / \mathrm{m}^{3}$ is given by the product of the flow $Q / \mathrm{m}^{3} \mathrm{~s}^{-1}$ and the time change $\Delta t / \mathrm{s}$ :

$$
\Delta V=Q \cdot \Delta t .
$$

The bulk modulus of elasticity $K_{\mathrm{SYS}, \mathrm{H}}$ of the system consisting of the hoses $\mathrm{H} 1$ and $\mathrm{H}$, the pipe $\mathrm{P} 1$ and oil can be determined in a similar manner.

Table 2. The experimentally measured values of the bulk modulus of elasticity of the investigated systems.

\begin{tabular}{|c|c|c|}
\hline & $\begin{array}{c}\text { Air-containing } \\
\text { system }\end{array}$ & $\begin{array}{c}\text { Partly deaerated } \\
\text { system }\end{array}$ \\
\hline$K_{\mathrm{SYS}, \mathrm{P}} / 10^{9} \mathrm{~Pa}$ & 1.198 & 1.277 \\
\hline$K_{\mathrm{SYS}, \mathrm{H}} / 10^{9} \mathrm{~Pa}$ & 0.954 & 0.989 \\
\hline
\end{tabular}

The influence of undissolved air and hoses on reduction in bulk modulus of elasticity (see table 1 and table 2) of the investigated systems is visible. 


\section{Mathematical model of experimental equipment}

The mathematical model was created using Matlab SimHydraulics (see figure 6). The hydraulic pump HP is a pressure source with a constant flow rate, which was experimentally measured. Oil flows through the check valve $C V$, the hose $H 1$, the inlet pipe $P 1$, the stop valve $\mathrm{SV} 1$, the pipe $\mathrm{P}$, the stop valve SV2, the waste pipe P2 and the hose $\mathrm{H} 2$ into the tanks $\mathrm{T}$ and $\mathrm{T} 1$. In the case of closing of the stop valves SV1 or SV2, hydraulic oil flows through the relief valve RV. There are included also the blocks for valve control (i.e. the blocks Control of SV1 and Control of SV2), the blocks for flow and pressure measurement (i.e. FS and PS), the solver block (i.e. Solver Configuration) and the block for liquid definition (i.e. Custom Hydraulic Fluid) in the investigated hydraulic circuit. The block Time is used to adjust the time step of scanning $\Delta t$, which was same as in the case of the experimental measurements (i.e. $\Delta t=0.001 \mathrm{~s})[8]$.

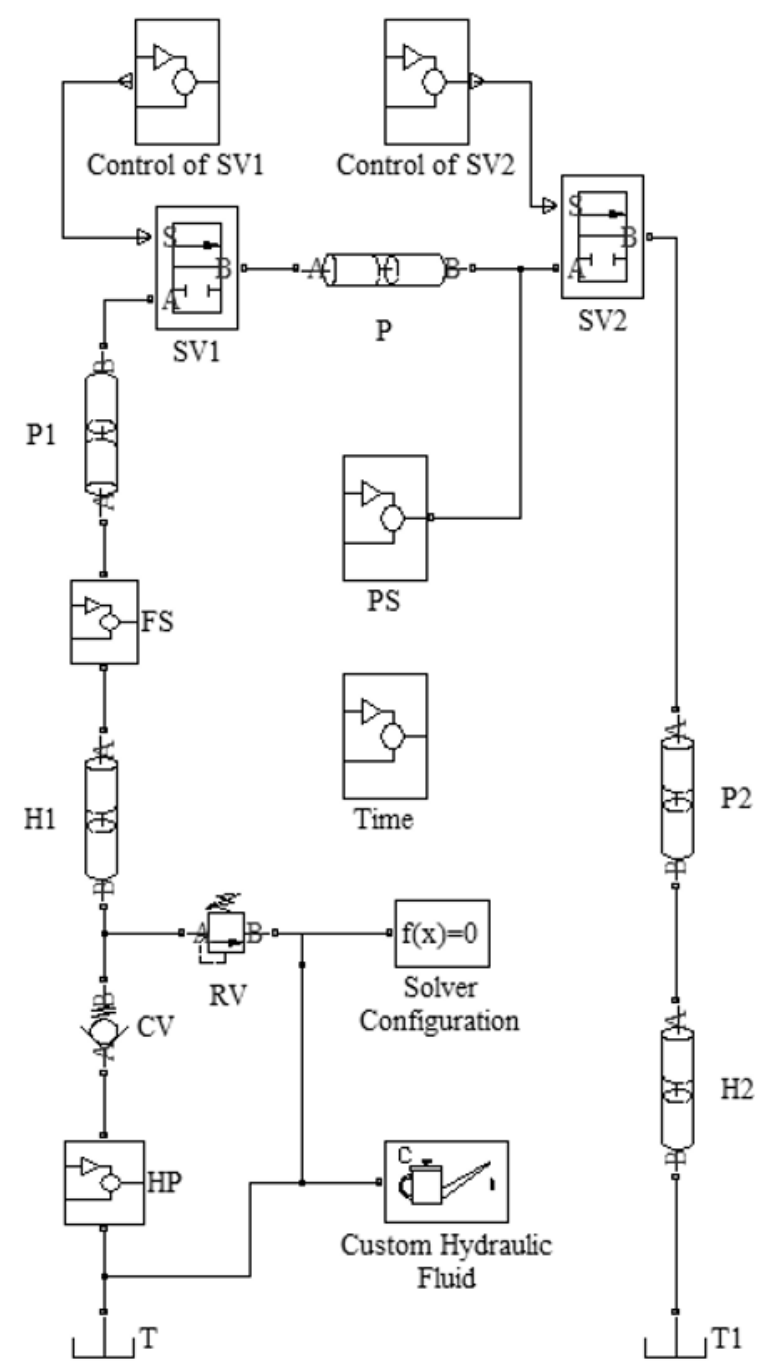

Fig. 6. Mathematical model created in Matlab SimHydraulics.

\section{Results of mathematical simulations and experimental measurements}

Time dependencies of pressure increase were simulated for two types of hydraulic systems. The first system consists of the hose $\mathrm{H} 1$, the pipe $\mathrm{P} 1$, the pipe $\mathrm{P}$ and hydraulic oil. The second system includes the hose H1, the pipe $\mathrm{P} 1$, the hose $\mathrm{H}$ and hydraulic oil. The simulated dependencies were subsequently compared with the experimentally determined dependencies that were described in the chapter 3.2.

\subsection{Simulation of line $\mathrm{H} 1+\mathrm{P} 1+\mathrm{P}+$ oil}

All model parameters are known for this simulation. Only the bulk modulus of elasticity of hydraulic oil and undissolved air content are unknown. It is especially necessary to enter the bulk modulus of elasticity of oil and the undissolved air content at parameter setting of investigated liquid in SimHydraulics. The oil bulk modulus of elasticity and the undissolved air content in liquid at atmospheric pressure were determined by comparison of the experiment and the mathematical model (see figure 7). Air amount in oil was observed by comparison of the numerically determined and the experimentally obtained start-up curve (see figure 7).

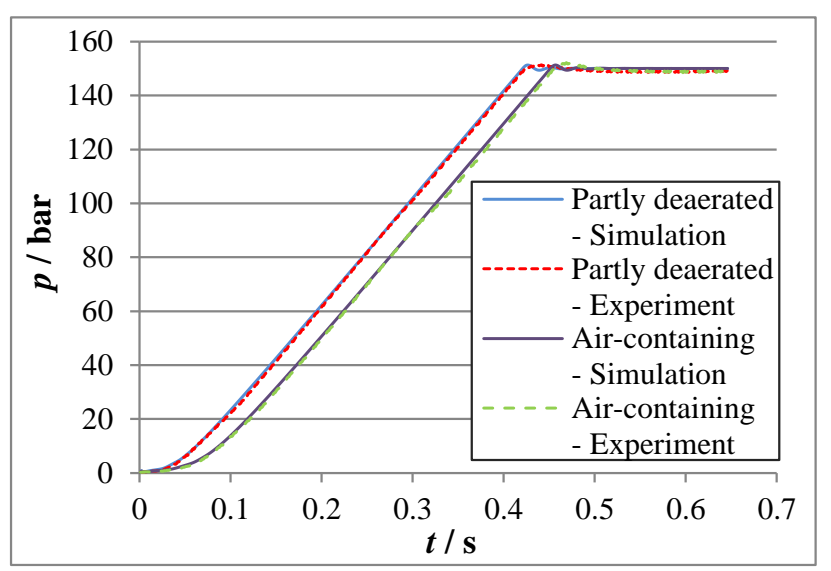

Fig. 7. Comparison of mathematical simulations and experimental measurements of air-containing and partly deaerated oil for the system $\mathrm{H} 1+\mathrm{P} 1+\mathrm{P}+$ oil.

Table 3. Values of the bulk modulus of elasticity and the undissolved air content required for mathematical simulations.

\begin{tabular}{|c|c|c|}
\hline Oil & $\begin{array}{c}\text { Bulk modulus of oil } \\
\text { without air } K / 10^{9} \mathrm{~Pa}\end{array}$ & $\begin{array}{c}\text { Undissolved air } \\
\text { content } \alpha / \%\end{array}$ \\
\hline Air-containing & 2.05 & 0.26 \\
\hline Partly deaerated & 2.05 & 0.16 \\
\hline
\end{tabular}

It is possible to verify undissolved air contents by calculation on the basis of experimental measurements of the bulk modulus of elasticity in the oil/pipe $\mathrm{P}$ system (see chapter 3.1). Level changes $\Delta h_{\mathrm{i}}$ were measured in the measuring tube MT for both oil types in terms of their aeration. In the case of air-containing oil, the level change 
$\Delta h_{1}=0.083 \mathrm{~m}$. Similarly for partly deaerated oil, the level change $\Delta h_{2}=0.075 \mathrm{~m}$. It can be concluded that the deaerated air volume $V_{\text {a }}$ (or the undissolved air volume) is given by the equation:

$$
V_{\mathrm{a}}=\frac{\pi \cdot d_{0}^{2}}{4} \cdot\left(\Delta h_{1}-\Delta h_{2}\right) .
$$

The change of undissolved air content $\alpha$ is expressed by the formula:

$$
\alpha=\frac{V_{\mathrm{a}}}{V_{\mathrm{O}, \mathrm{P}}}=0.00098 \cong 0.001 .
$$

Eventually:

$$
\alpha=\frac{V_{\mathrm{a}}}{V_{\mathrm{O}, \mathrm{P}}} \cdot 100 \cong 0.1 \% \text {. }
$$

The content change $\alpha$ was similarly determined from the previous mathematical simulations (see table 3 ):

$$
\alpha=\alpha_{1}-\alpha_{2}=0.26-0.16=0.1 \% .
$$

Undissolved air amount has a big influence on ramp of the curves (see figure 8). The rise time increases in general with increasing air amount. This is reflected in higher compressibility of air compared with oil. The pressure dependencies are almost linear after a phase of intensive air compression. The curves of pressure increases for different air contents are parallel at constant flow, system volume, oil bulk modulus of elasticity and elasticity of pipes and hoses.

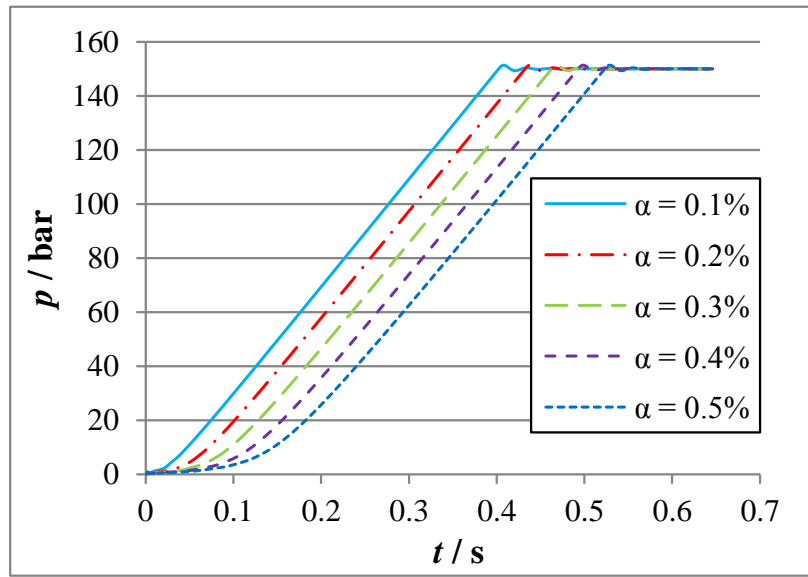

Fig. 8. Influence of undissolved air content on ramp of curves.

\subsection{Simulation of oil/pipe P system}

The model with the pipe $\mathrm{P}$ (without the supply lines H1 and P1) was used for the simulation of the pressure change depending on the time (see figure 9). The secant bulk modulus of elasticity of the oil/pipe P system was evaluated from a time change of the pressure at given values of oil volume and flow in the pipe P. The bulk modulus was subsequently compared with the experimentally determined bulk modulus of elasticity of the oil/pipe P system (see chapter 3.1).

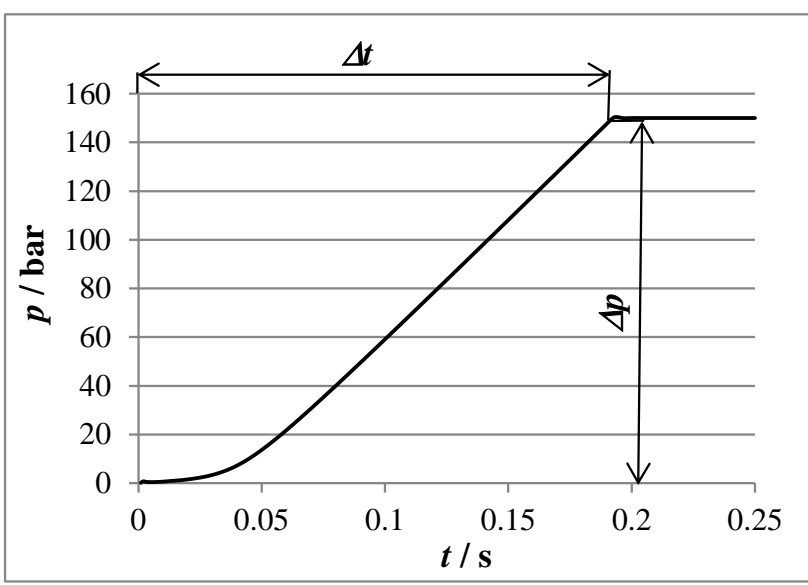

Fig. 9. Simulation of pressure increase depending on time of oil/pipe $P$ system.

The bulk modulus of elasticity of the oil/pipe $\mathrm{P}$ system determined from the time dependence of the pressure (see figure 9) was calculated (see chapter 3.1) according to the formula (5). Similarly, the oil bulk modulus of elasticity was obtained from the equation (6). The pressure change $\Delta p$ was deducted from the figure 9. The oil volume change $\Delta V_{\mathrm{O}, \mathrm{P}}$ at the hydraulic pump flow $Q=1.96 \mathrm{dm}^{3}$ is given by the equation:

$$
\Delta V_{\mathrm{O}, \mathrm{P}}=Q \cdot \Delta t
$$

The time change $\Delta t$ was also deducted from the figure 9 .

Table 4. Comparison of the oil bulk modulus of elasticity $K_{\mathrm{O}}$ and the bulk modulus of elasticity $K_{\mathrm{O}, \mathrm{P}}$ of the oil/pipe P system determined by means of experiment and simulation.

\begin{tabular}{|c|c|c|}
\hline & $\begin{array}{c}\text { Air-containing } \\
\text { system }\end{array}$ & $\begin{array}{c}\text { Partly deaerated } \\
\text { system }\end{array}$ \\
\hline$K_{\mathrm{O}, \mathrm{P}} / 10^{9} \mathrm{~Pa}$ - experiment & 1.496 & 1.655 \\
\hline$K_{\mathrm{O}, \mathrm{P}} / 10^{9} \mathrm{~Pa}$ - simulation & 1.501 & 1.658 \\
\hline$K_{\mathrm{O}} / 10^{9} \mathrm{~Pa}$ - experiment & 1.557 & 1.730 \\
\hline$K_{\mathrm{O}} / 10^{9} \mathrm{~Pa}$ - simulation & 1.566 & 1.736 \\
\hline
\end{tabular}

It is evident (see table 4) that the bulk modulus of elasticity of oil and the oil/pipe P system determined by the mathematical simulation correspond with the experimentally determined values in the chapter 3.1 .

\subsection{Simulation of line $\mathrm{H} 1+\mathrm{P} 1+\mathrm{H}+$ oil}

The mathematical simulation of the pressure increase depending on time for the system consisting of the hose $\mathrm{H} 1$, the pipe $\mathrm{P}$, the hose $\mathrm{H}$ and oil (see figure 6) was performed in the same way as in the chapter 5.1. 

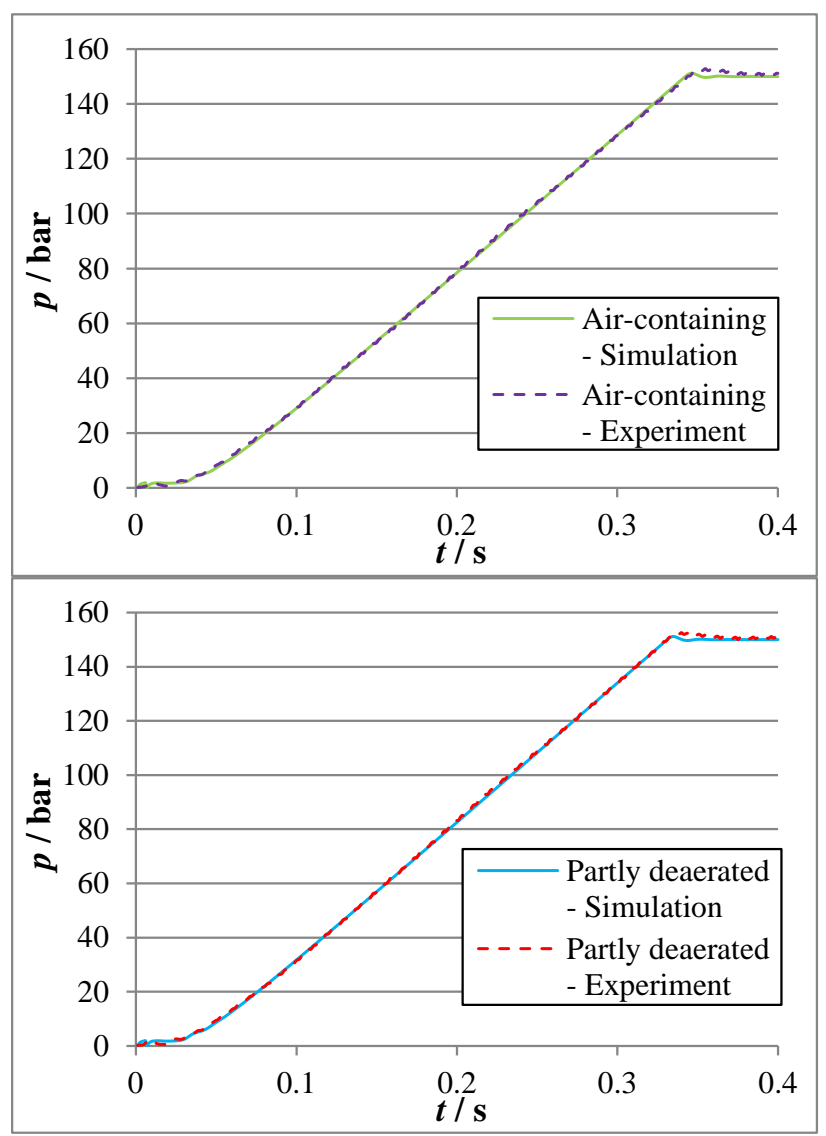

Fig. 10. Comparison of mathematical simulations and experimental measurements of air-containing and partly deaerated oil for the system $\mathrm{H} 1+\mathrm{P} 1+\mathrm{H}+$ oil.

The undissolved air content in liquid at atmospheric pressure was similarly determined by same methodology as in the chapter 5.1, namely by comparison of the experiment and the mathematical model (see figure 10).

Table 5. Values of the bulk modulus of elasticity and the undissolved air content required for mathematical simulations.

\begin{tabular}{|c|c|c|}
\hline Oil & $\begin{array}{c}\text { Bulk modulus of oil } \\
\text { without air } K / 10^{9} \mathrm{~Pa}\end{array}$ & $\begin{array}{c}\text { Undissolved air } \\
\text { content } \alpha / \%\end{array}$ \\
\hline Air-containing & 2.05 & 0.28 \\
\hline Partly deaerated & 2.05 & 0.23 \\
\hline
\end{tabular}

\subsection{Simulation of oil/hose $\mathrm{H}$ system}

The same methodology as in the case of the oil/pipe $\mathrm{P}$ system was applied for the simulation of the oil/hose $\mathrm{H}$ system. The pressure increase depending on time at the hose $\mathrm{H}$ (without the supply lines $\mathrm{H} 1$ and $\mathrm{P} 1$ ) was simulated by means of the mathematical model. The bulk modulus of elasticity of the oil/hose system was evaluated in this case. The modulus was subsequently compared with the experimentally determined values.
Table 6. Comparison of the bulk modulus of elasticity $K_{\mathrm{O}, \mathrm{H}}$ of the oil/hose $\mathrm{H}$ system determined by means of experiment and simulation.

\begin{tabular}{|c|c|c|}
\hline & $\begin{array}{c}\text { Air-containing } \\
\text { system }\end{array}$ & $\begin{array}{c}\text { Partly deaerated } \\
\text { system }\end{array}$ \\
\hline$K_{\mathrm{O}, \mathrm{H}} / 10^{9} \mathrm{~Pa}$ - experiment & 0.869 & 0.891 \\
\hline$K_{\mathrm{O}, \mathrm{H}} / 10^{9} \mathrm{~Pa}$ - simulation & 0.867 & 0.892 \\
\hline
\end{tabular}

It is evident (see table 6) that the values of the bulk modulus of elasticity of the oil/hose $\mathrm{H}$ system determined by the mathematical simulation correspond with the experimentally determined values in the chapter 3.1 .

\section{Conclusions}

The aim of this work was to experimentally determine the bulk modulus of elasticity of oil, the oil/pipe $\mathrm{P}$ system and the oil/hose $\mathrm{H}$ system. The mathematical model of the experimental equipment was described in Matlab SimHydraulics. The bulk modulus of oil and the undissolved air content were obtained by comparison of the experimentally determined and the simulated time dependencies of the pressure increase in the investigated system. These quantities belong to important input parameters of the numerical model. The simulation model was verified by comparison of the simulated time dependence of the pressure increase with the experiment in the oil/pipe $\mathrm{P}$ system and the oil/hose $\mathrm{H}$ system. The experimentally obtained bulk modulus of elasticity of the oil/pipe $\mathrm{P}$ system and the oil/hose $\mathrm{H}$ system are in accordance with the values that were observed from the mathematical simulations.

\section{References}

1. P. K. B. Hodges, Hydraulic Fluids (ButterworthHeinemann, 1996)

2. D. Will, T. Gebhardt, Hydraulic Grundlagen, Komponenten, Schaltungen (Springer, Berlin, 2008)

3. J. Kopáček, J. Šubert, Strojírenská výroba 28, 12 (1980)

4. J. Kopáček, Strojírenství 36, 656-662 (1986)

5. A. A. Conte, J. L. Hammond, Development of a High Temperature Silicone Base Fire-resistant Hydraulic Fluid (Aircraft and Crew Systems Technology Directorate, Warminster, 1980)

6. B. J. Bornong, V. Y. S. Hong, Investigation of Compressible Fluids for Use in Soft Recoil Mechanisms (Large Caliber Systems Laboratory ARRADCOM, Dover, 1977)

7. L. Hružík, M. Vašina, Acta Hydraulica et Pneumatica 1, 12-16 (2009)

8. The MathWorks, Matlab Simulink User's Guide, SimHydraulics User's Guide (USA, 2007) 